\title{
Analysis of bioenergy by using linear regression
}

\author{
Muhammad Shahid Iqbal ${ }^{1,2} \cdot$ Tamoor Khan $^{3} \cdot$ Samina Kausar $^{4} \cdot$ Luo Bin $^{1}$
}

(c) Springer Nature Switzerland AG 2019

\begin{abstract}
Prediction of bioenergy production is challenging in the machine learning field. In this article, bioenergy production data from different countries (Russian Fed, Turkey, Armenia, Azerbaijan and total Eurasia) were analyzed to predict future bioenergy production in these countries using the linear regression. Data on output production of bioenergy in megawatt were obtained from the International Renewable Energy Agency, and (MW). We implemented the linear regression method redundant to predict the future production of bioenergy data and attained good accuracy. The aforementioned method is applicable to developing countries and can be used to predict bioenergy production and formulate new policies that are adapted to an increasing population in a particular country. Our results (average accuracy is $49.61 \%$ ) revealed that bioenergy production levels in developing countries are not sufficient to cater for bioenergy needs of fast growing populations. Thus we recommend that governments should formulate adequate policies aimed at improving bioenergy production.
\end{abstract}

Keywords Bioenergy · Energy production · Linear regression model · Yearly production · International renewable energy agency

\section{Introduction}

Bioenergy is renewable energy made available from materials derived from biological sources. Bioenergy is organic material, which stores energy from sunlight, in the form of chemical energy that can be used as a fuel in the form of liquid biofuels or biogas. Biomass may include wood waste, wood, straw, sugarcane, manure and many other products, which are by-products of a variety of agricultural processes [1-6] Concerns about energy security, climate policy and search for new alternative sources of agricultural income have greatly increased interest in bioenergy and fossil fuels. A number of studies have projected considerable growth in bio-energy use, and thus important changes have been made in both energy systems and land use [1,4-8]. However, the use of bioenergy and its implications have been for some time a subject of a fierce debate
$[5,9-16]$. One of the critical issues linked to bioenergy production is the emission of greenhouse gases and finding a balance between bioenergy production and minimizing environmental pollution has always been elusive. Several studies have published the estimates of potential and actual use of bioenergy under different scenarios [5, 17-23]. Previous studies have reported on the different modes of producing bioenergy (biomass) [3, 5, 24-26]; however, none of them are able to predict with accuracy the future implications of bioenergy production. Biomass is commonly used to increase yields of agricultural crops via fertilization and irrigation, and may similarly increase biomass yields for perennial bioenergy crops [5, 26-29]. In this paper we have suggested a predictive method for future bioenergy production using the technique of machine learning, an evaluation method that automates the creation of evaluation models. Machine learning uses

$\triangle$ Muhammad Shahid Iqbal, nawabishahid@yahoo.com | 'School of Computer Science and Technology, Anhui University, Hefei, China. ${ }^{2}$ Department of Computer Sciences, Air University, Islamabad, Pakistan. ${ }^{3}$ School of Economic Information Engineering, Southwestern University of Finance and Economics, Chengdu, People's Republic of China. ${ }^{4}$ School of Computer Engineering and Science, Shanghai University, Shanghai 200444, China. 
artificial intelligence based on the idea that systems can learn from data, identify patterns and make decisions with minimal human intervention. Previously, machine learning techniques have been used to predict a number of other fields (linear regression technique) $[30,31]$ stock price (deep belief network) [32] price movement (LSTM neural network algorithm) [33], real Estate price [34], amazon spot price (ANFIS model) [35], closing price prediction. (two dimensional principal component analyses) [36], electricity price prediction (neural network model) [37], housing price (neural network) [38]. However, previous studies did not focus on the bio energy; we have predicted the future bio energy production. As many countries around the world are trying to increase bioenergy production. It is anticipated that the main outcome of this research will critically influence the rationale behind bioenergy production and determine the future of bioenergy production. This paper focused mainly on bioenergy prediction in Eurasian countries, using linear regression model to predict the future bioenergy production in the Russian Federation, Turkey, Armenia, Azerbaijan and the whole Eurasia. The time series data were collected from 2006 to 2016. Because the data size was small, the linear regression model and the prediction accuracy was $49.61 \%$.

\section{Bioenergy production}

The trend nowadays is to promote bioenergy as a fuel on a large scale. A number of key factors are considered when promoting bioenergy production, including: (1) greenhouse emission reduction, (2) direct impact on biodiversity or potential biodiversity loss and food production, (3) ecological problems, such as water shortage and (4) costs associated with bioenergy production Estimation studies usually put emphasis on the entire potential of associated costs and bioenergy by a set of nominal application criteria $[13,17,18,20-22]$ and bioenergy is a renewable energy source made from biomass [40-43]. In strategic terms, the discussion on the penalties of extensive bioenergy usage has managed by rule manufacturers in sustainability principles, such as those careful in present EU legislature. The biomass main sources are shown in Fig. 1.

\section{Problem definition}

\subsection{Problem statement}

This study proposes to predict future production using a model of bioenergy production using agricultural analysis and linear regression. The Eq. 1 show that the prediction of the problem of bioenergy production is formally defined as follows: $N$ number of training samples $\{[(X 1, Z 1),(X 2, Z 2) \ldots$ $(X n, Z n)$ where $X 1$ is the annual vector of bioenergy a1, and $A$ is the set of $n$ countries in which $A=\{a 1, a 2, a 3, \ldots a n\}$, . In Eq. 2 shows the total number of functions is $\left\{X \mid\right.$ total $\left.=R^{\wedge} \mathrm{m}\right\}$ and $\mathrm{m}$, and the status of bioenergy production (increased or decreased) is $\mathrm{Zi}$, where the number of features is $\mathrm{Z}$ total liyes, no\}. The following predictive function is proposed to predict annual production of bioenergy:

$$
Z=f\left(\frac{A}{X}\right)
$$

$$
f\left(\frac{A}{X}\right)=\left[\begin{array}{l}
\geq 0=\text { if } Z=\text { yes increasing } \\
<0=\text { if } Z=\text { no decreasing }
\end{array}\right]
$$

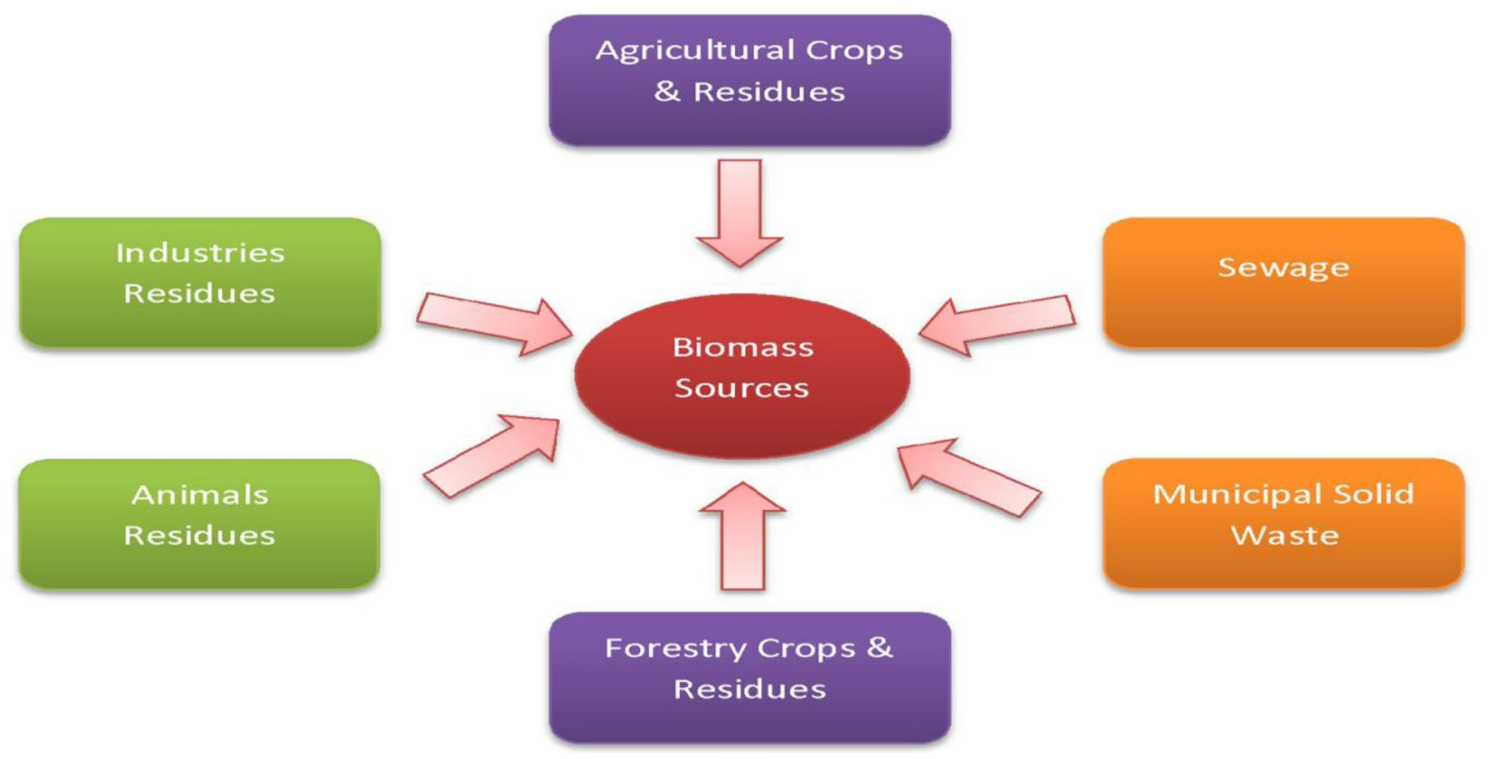

Fig. 1 Bioenergy sources 
The Eq. 3 show the primary objective of the learning task is to study a predictive function $f^{\wedge}=($.) or to increase or decrease the predicted bioenergy production.

$Z^{\wedge}=f^{\wedge}\left(\frac{A}{X}\right)$

\section{Materials and methods}

Bioenergy prediction is a challenging task in the field of machine learning. The main challenge is to guide government and bioenergy production organizations, especially in countries where less energy is produced as compared to energy use or needs. A number of learning methods have been applied to predict the stock market, including Genetic Algorithm, Artificial Neural Network and Support Vector Machine. The Artificial Neural Network is the main method that is widely used in this field. Therefore, to understand how ANN can be used to predict bioenergy production in agriculture, techniques that enhance ANN's performance are reviewed. Price prediction can be demonstrated by two methods: the technical method by which statistical data analysis is performed and the fundamental method by which all available details and growth agents that affect bioenergy production are considered. These methods are carried out on present and historical data with the aim of forecasting bioenergy. Technical analysis with the linear regression algorithm was used in this paper to predict bioenergy production. Data on the production of bioenergy from Eurasia were obtained from available public records and used for prediction. Linear Regression is a well-established technique in a wide range of applications and has been widely studied for its bioenergy prediction capabilities. However, the inputs considered are mostly derived from the data within the annual bioenergy data itself. Such separation could ignore the factors affecting production. Consideration of publicly available bioenergy prediction data can improve the accuracy and future bioenergy production. Figure 2 shows the predictive model of bioenergy.

\subsection{Prediction of bioenergy production using machine learning}

For statistical classification techniques, the machine learning algorithm with linear regression was used and the results were determined by one or more independent variables. The natural outcome of the model of linear regression is categorical. The model of linear regression was represented as follows (see Eq. 4):

$Y_{i}=\beta_{0} 1+\beta_{p} x_{i 1}+\cdots+\beta_{p} x_{i p}=X^{\top} i \beta+\varepsilon_{i}, \quad i=1 \ldots n$

T denotes transposing, so that $X^{T} i \beta$ is the inner product between xi and $\beta$ vectors (see Eq. 5). The form of the vector is

$\mathrm{Y}=\mathrm{X} \beta+\varepsilon$

Therefore, the confidence interval of $E\left(y \mid x^{*}\right)$ is the average expected value of $y$ for a given $x^{*}$ (see Eq. 6).

$y^{\wedge} \pm \mathrm{t}_{n-2}^{*} S_{y} \sqrt{\frac{1}{n}+\frac{\left(x^{*}-x^{\prime}\right)^{2}}{(n-1) s_{x}^{2}}}$

where Sy is the standard deviation from the residues, the residual error in the $R$ regression output is calculated as and as Sy (see Eq. 7).

$s_{y}=\sqrt{\frac{\sum\left(y_{i}-y^{\wedge}\right)^{2}}{n-2}}$

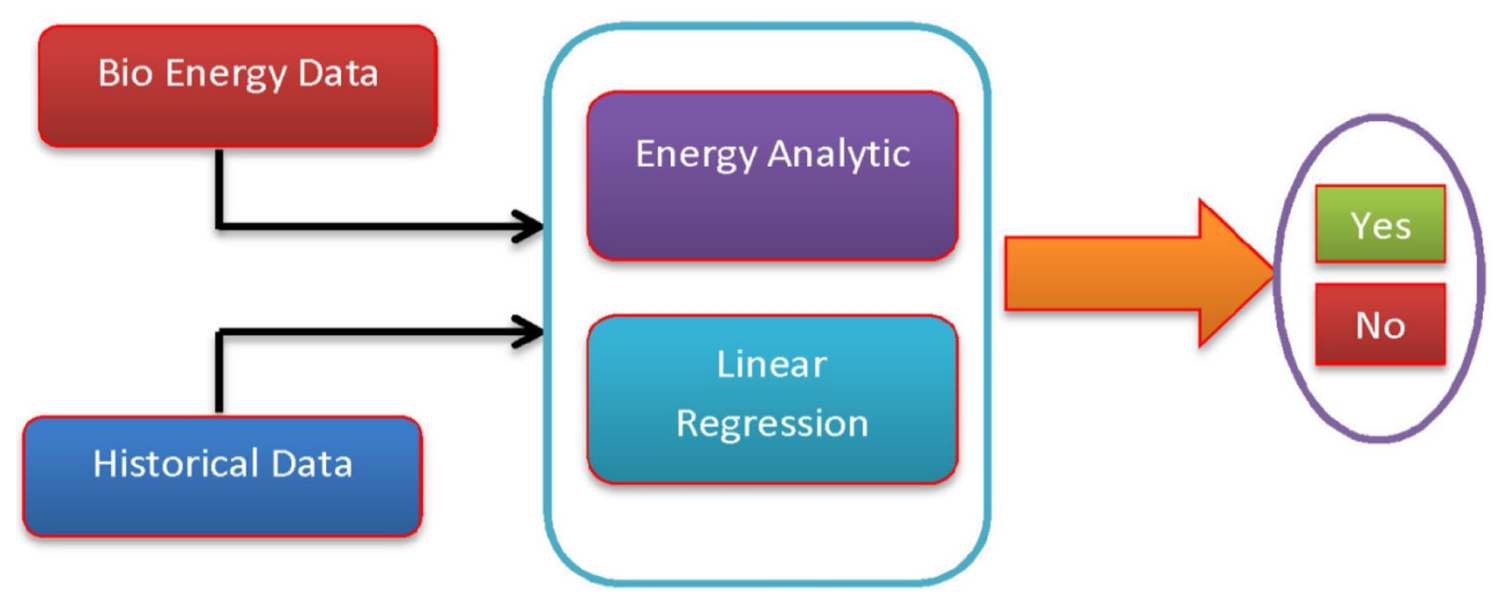

Fig. 2 Bioenergy production prediction model 
The proposed model consists of vectors with dimensional feature space $m$. The real number range is - range to + range $(-\infty$ to $+\infty)$ in the space $x$ points feature, which projects it on $\mathrm{m}$ and converts it to a real number $\mathrm{z}$ (see Eq. 8).

$Z=C+m \cdot x=C+m_{1} x_{1}+m_{2} x_{2}+\cdots+m_{d} x_{d}$

Future prediction is a difficult task, whether in stock market or bioenergy forecasting. Projection of production trends for bioenergy involves predicting hidden relationships and characterizing data intensity, noise and high degree of uncertainty. In bioenergy prediction, forecasts are made for future production (next year) of 'high' or 'low'. Therefore, linear regression method outfits fine for prediction of bioenergy and trend prediction. Highly connected features are trained for the linear regression model. The training data model is built and used to test data. The training data model is constructed and used to test data. Complete features were highly connected and accuracy of 49.61 percent. Precision was calculated by confusion matrix.

Accurcy
$=\frac{(\text { True Positive })+(\text { True Negative })}{(\text { True Positive })+(\text { False Positive })+(\text { False Negative })+(\text { True Negative })}$

where genuinely positive (TP) is an upward trend and is classified as upward. True Negative (TN), a downward trend, is described as downward. False Positive (FP) is a downward trend, but it is categorized as upward. False negative (FN) is a rising trend categorized as downward. Figure 3 shows the detailed steps of this method.
Fig. 3 Bioenergy future production method

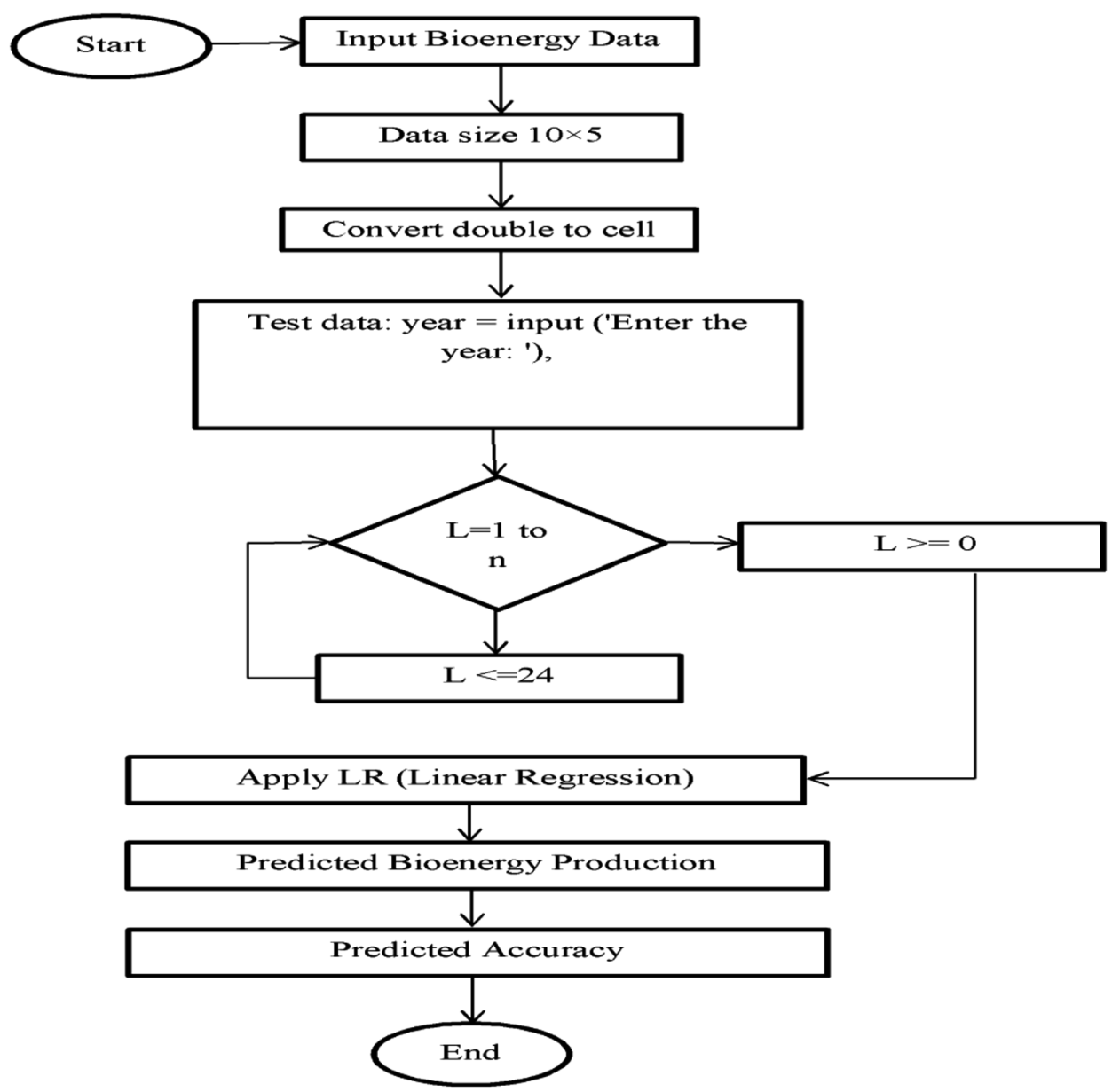




\section{Algorithm 1:}

Bioenergy production prediction

Input: $\mathrm{X}$ is the input

Output: Future bioenergy production prediction is $\mathrm{P}$

Algorithm:

Step 1: take matrix $M$ of data for the last one year, data size (15)

Step 2: take matrix P of data for the previous / last ten years, data size 10

Step 3: make a sliding window and the window size is 16 for each matrix P as W1, W2...

W10

Step 4: calculate the Euclidean distance of s. D10

Step 5: Select matrix Wi as $\mathrm{Wi}=$ corresponding matrix (min Di) $[1,10]$

Step 6: for $\mathrm{I}=1$ ton 1)

- 1) calculate the moving average (MA) of two matrix D and save as Q 2)

- 2) calculate the CMA (central moving average) of matrix Q and save as R.

- 3) calculate the mean Q matrix

- 4) calculate the mean of matrix $\mathrm{R}$

- 5) calculate the average of both mean and apply LR (linear regression) and predict the $P$.

- Add P to previous data for getting prediction

\subsection{Data set}

Time sequence data were collected from the International Renewable Energy Agency (IRENA). Annual time data sequences from 2006 to 2016 were used to inspect the association between bioenergy GDP and bioenergy outputs. The variables used in this study are: production of bioenergy, output of the Russian Fed in (MW), output of Turkey is (MW) and output of Armenia is (MW), output of Azerbaijan (MW) and output of total Eurasia in (MW). Table 1 provides a detailed description of the datasets.

Table 1 Detailed description of datasets

\begin{tabular}{lcl}
\hline Bioenergy production of Eurasia countries & \\
\hline Countries (bioenergy) & Study range & $\begin{array}{l}\text { Production (MW) } \\
\text { Mega watts }\end{array}$ \\
\hline Russian Fed & $2006-2016$ & 12,545 \\
Turkey & $2006-2016$ & 1789 \\
Armenia & $2006-2016$ & 154.000 \\
Azerbaijan & $2006-2016$ & 6.000 \\
Eurasia & $2006-2016$ & 15,862 \\
\hline
\end{tabular}

Data were taken from the (International Renewable Energy Agency)

\section{Results and discussion}

\subsection{Russian federation}

The Russian Bioenergy Organization is an industrialized holding corporation in the arena of fuel energy, biotechnology and engineering. Assets of the corporation make a complete production cycle available for industrial engineering, processing and peat extraction, distribution and production of finished products generating electricity and heat. Bioenergy production in Russian Fed in 2006 was 1667 (MW) and in 2008, the production of bioenergy decreased and reached 1253 (MW). Production in 2010 was 1197 (MW). Production increased in 2014 and reached 1370 (MW), and in 2016, production was also 1370 (MW). The production of bioenergy from 2006 to 2016 is shown in Fig. 4, and the forecast of bioenergy production is shown in Figs. 4 and 5. We predicted the production of bioenergy from 1980 (past) to 2030.

\subsection{Turkey}

Turkey has a high potential for biogas production [1]. More than 85 million tons of animal wastes are produced annually, which is estimated to over 1.8 million tons of oil (toe) equivalent. When plant waste is included, the potential rises to over 5.3 million tons of oil equivalent 
Fig. 4 a Bioenergy of Russian Fed, the graph shows bioenergy production and predicted bioenergy. $\mathbf{b}$ Bioenergy of

Turkey, the graph shows bioenergy production and predicted bioenergy. c Bioenergy of Armenia, the graph shows bioenergy production and predicted bioenergy. $\mathbf{d}$ Bioenergy of Azerbaijan, the graph shows bioenergy production and predicted bioenergy. e Bioenergy of Eurasia, the graph shows bioenergy production and predicted bioenergy
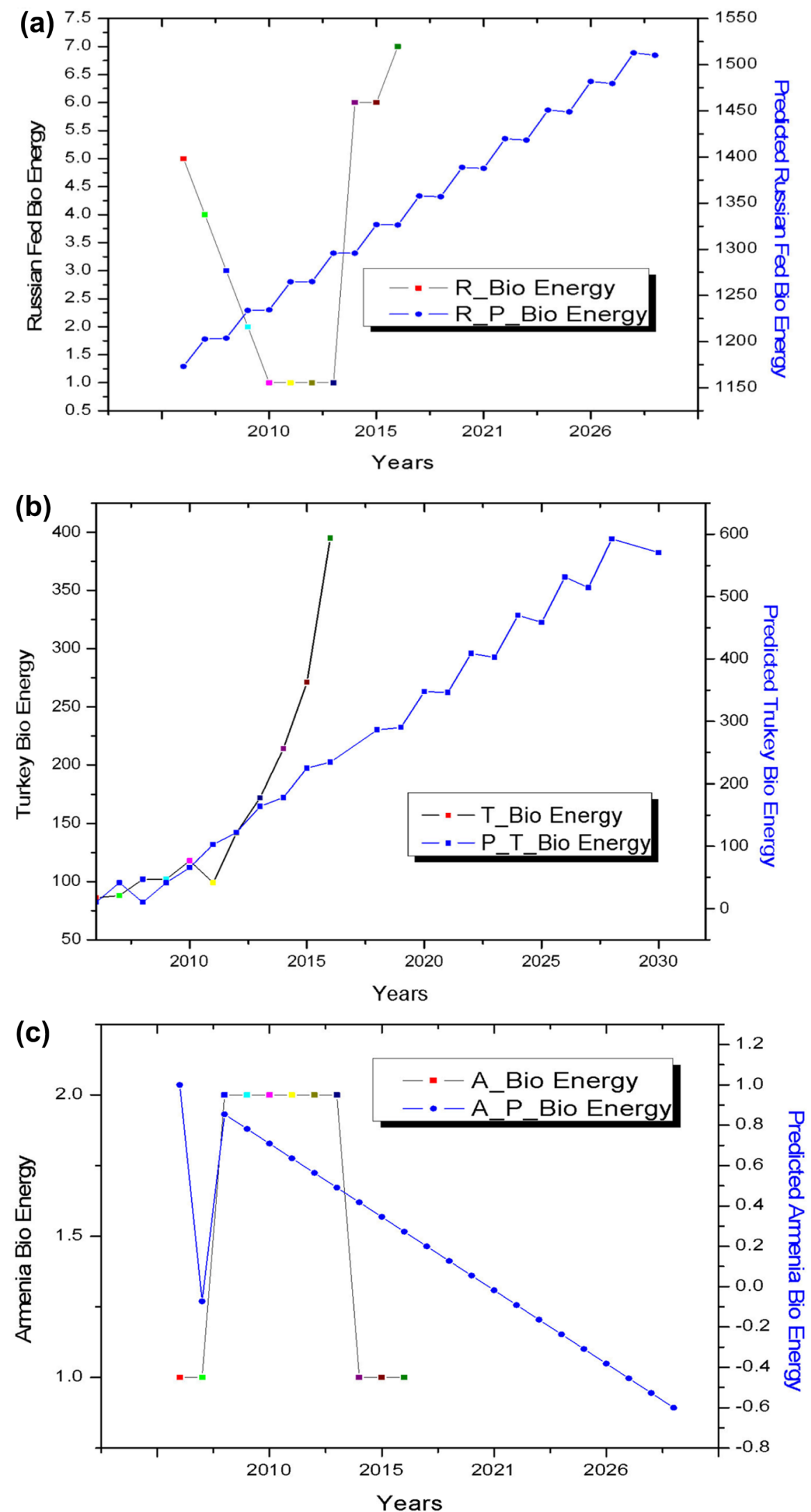
Fig. 4 (continued)
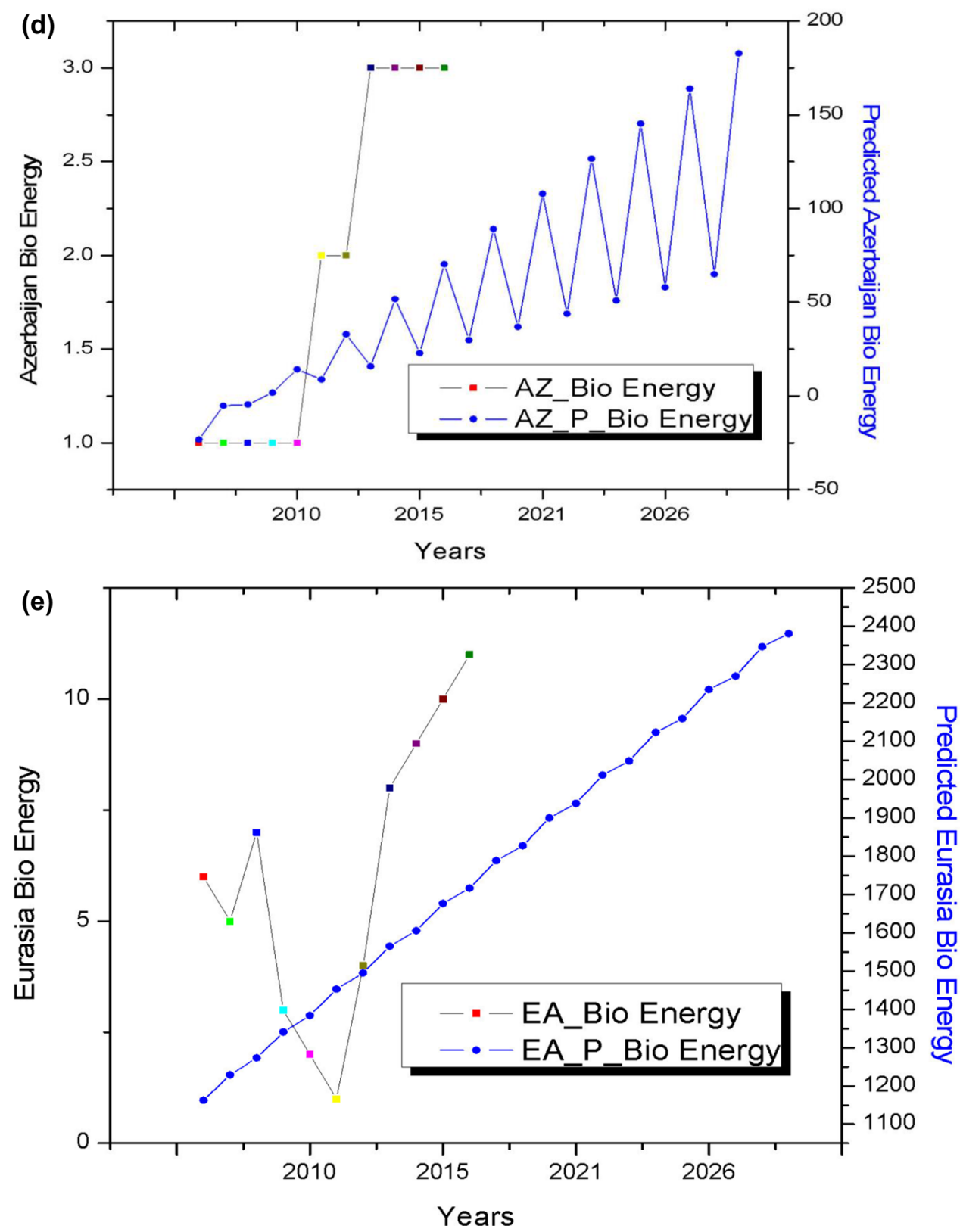

(toe). However, only 85 biogas facilities with 36 plants are currently in operation [1]. Eighty (80) MW of landfill power is in operation while $78 \mathrm{MW}$ is under construction [7]. Bioenergy production in Turkey in 2006 was 86 (MW) and in 2008 , the production of bioenergy increased and reached 102 (MW). Production in 2010 was 118 (MW). Production increased in 2014 and reached 214 (MW), and in 2016, production increased and reached 395 (MW). Bioenergy production increased from 2006 to 2016 (Fig. 4), and the forecast of bioenergy production is shown in Fig. 4. We have predicted the production of bioenergy from 1980 to 2030.

\subsection{Armenia}

Bioenergy production in Armenia in 2006 was 0 (MW) and in 2008, the bioenergy production increased and reached 1 (MW). Production in 2010 was also 1(MW). Once again, production decreased in 2014 and reached 0 (MW), and in 2016, there was no production, 0 (MW). The Upward and downward bioenergy production and no production trends from 2006 to 2016 are shown in Fig. 4. Forecast of bioenergy production is shown in Fig. 4. We have predicted the production of bioenergy from 1980 to 2030. 

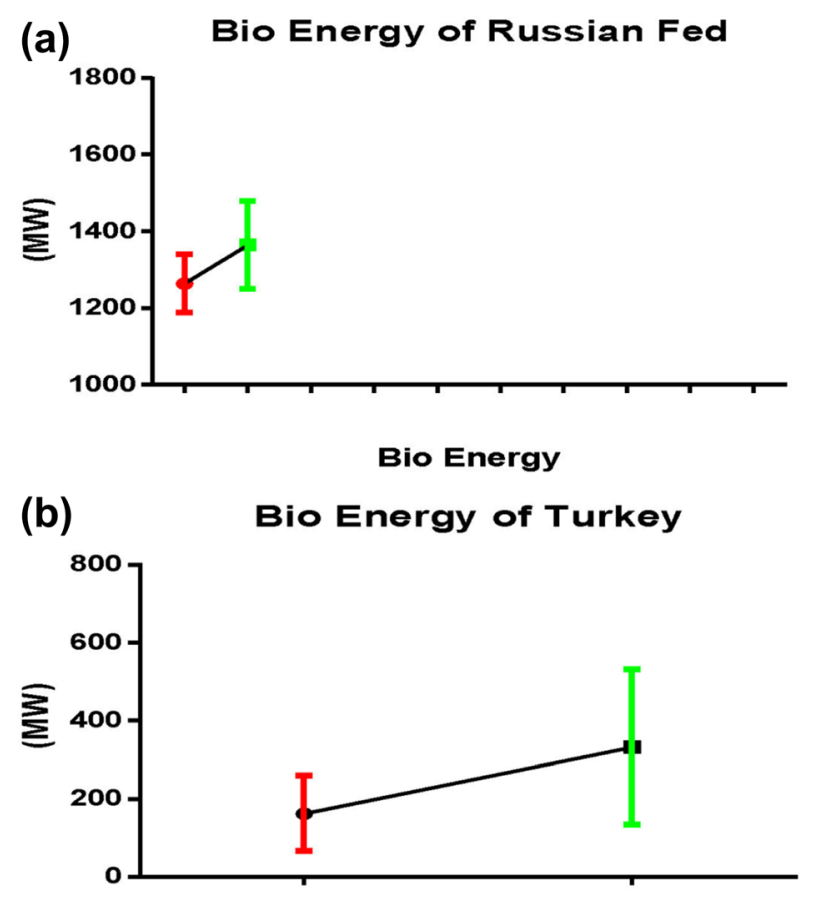

Bio Energy

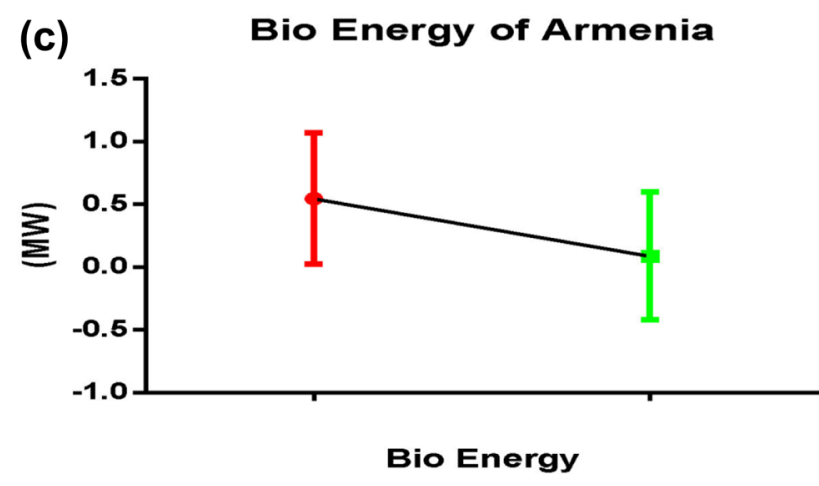

Fig. 5 a Error bars and mean connected of Bioenergy production (Russian Fed), b Error bars and mean connected of bioenergy production (Turkey), c error bars and mean connected of bioenergy production (Armenia), $\mathbf{d}$ error bars and mean connected of bioenergy production (Azerbaijan), e error bars and mean connected of bioenergy production (Eurasia)

\subsection{Azerbaijan}

Bioenergy is the biggest source of renewable energy nowadays and can generate electricity, heat and can also be used as transport fuel. This roadmap envisions, whole world total bioenergy supply increasing from $50 \mathrm{EJ}$ today to $160 \mathrm{EJ}$ in 2050, with $100 \mathrm{EJ}$ of $160 \mathrm{EJ}$ for generation of power and heat. In Azerbaijan, there was no bioenergy production from 2006 to 2010. In 2011, production increased and reached 1 (MW). In 2012 production was again 1 (MW). Production increased in 2014 and reached

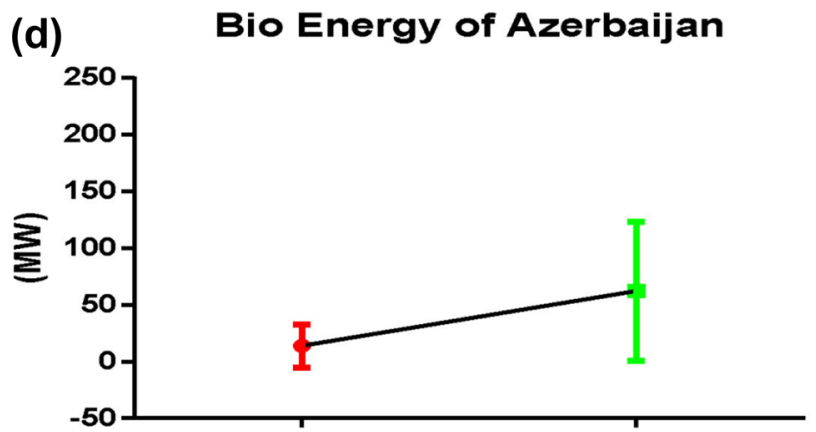

Bio Energy

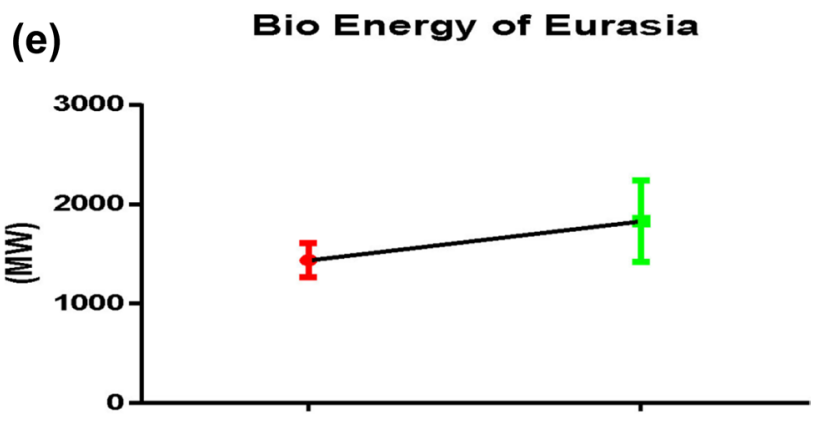

Bio Energy

Fig. 5 (continued)

38 (MW), and in 2016, production was again 38 (MW). An upward increase in bioenergy production (up) from 2006 to 2016 is shown in Fig. 4, and the forecast of bioenergy production is shown in Fig. 4. We have predicted the production of bioenergy from 1980 to 2030 .

\subsection{Eurasia}

Bioenergy production in Eurasia in 2006 was 1353 (MW) and in 2008, the production of bioenergy increased and reached 1356 (MW). Production in 2010 was 1316 (MW). Production increased in 2014 and reached 1662 (MW), and in 2016, production increased and reached 1803 (MW). An upward increase in bioenergy production (up) and a downward increase from 2006 to 2016 are shown in Fig. 4. The forecast of bioenergy production is shown in Fig. 4. We have predicted the production of bioenergy from 1980 to 2030 . Figure 5 shows two columns, one for original bioenergy production data and the second column shows predicted data. Each column has a mean value and the mean is plotted as the SD. The bar between the mean and SD shows the error bar and mean connections are shown in Fig. 5. 


\section{(a) Bio Energy 2016}

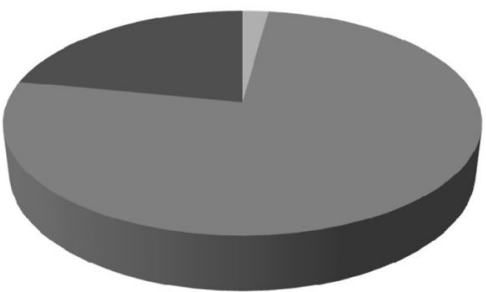

- Armenia

Azerbaijan

- Russian Fed

- Turkey

\section{(b) Bio Energy 2030}

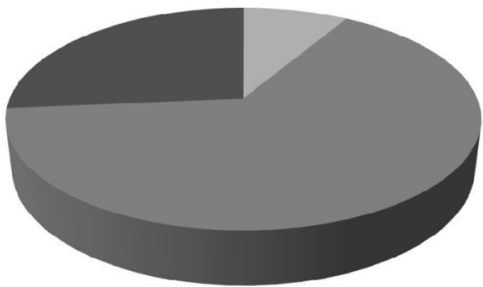

Armenia

Azerbaijan

- Russian Fed

- Turkey

Fig. 6 a Bio energy production of four countries till 2016 and b shows the predicted bioengry of four countries till 2030

\section{Discussion and recommendation}

Biomass energy is increasingly becoming a part of global renewable energy. World-wide, electricity generated from biomass is also on the rise. According to the UNEP report, in 2012 the total power capacity world-wide exceeded $1470 \mathrm{GW}$ and increased up to $8.5 \%$ from 2011. A large quantity of energy is consumed in the agriculture sector and waste from a number of crops, including coconut sugarcane and rice has become an energy-rich source of electricity [39]. This study has used data from RFED, Turkey, Armenia, Azerbaijan, and Eurasia as a whole nation on bioenergy production to predict future bioenergy growth. We used linear regression models for high accuracy to generate these predictions. Russian Fed bioenergy production in 2016 was 1370 (MW). According to our future predictions, in 2030, bioenergy production will be 1540.801 (MW). In
2016, bioenergy production in Turkey was 395 (MW) and the future prediction for 2030 will be 626.7197 (MW). In Armenia bioenergy production was 0 in 2016, and the future prediction for 2030 will be 0.74545 (MW). In Azerbaijan production was 38 (MW) in 2016, and the prediction for Azerbaijan will be 201.4236 (MW) in 2030. In Eurasia production was 1803 (MW) in 2016, and the prediction for bananas will be 2491.216 (MW). Figure 6 shows the bioenergy production in 2016 and future bioenergy production prediction in 2030.

Currently, there is a need to increase bioenergy production in Russian Fed, Turkey, Armenia, Azerbaijan and Eurasia. It is the government's responsibility to support all bioenergy organizations by providing them with all services that needed to increase bioenergy production. This prediction method is applicable to all developing countries. If developing countries can increase their bioenergy production to meet the demands of their increasing energy requirements, they will be in a better position to provide energy to their respective populations. Table 2 shows the result of bioenergy production.

\section{Conclusion}

Bioenergy production is important for any nation. Production depends upon services available to the bioenergy organizations, which totally depends on government bioenergy policies. If the government supports bioenergy production organizations, production will increase. In this study, we developed techniques for predicting bioenergy production using existing bioenergy production data, and we presented the results of the analysis. In the prediction model, we used linear regression model that periodically predicts the trends of bioenergy production. Algorithms that were used had a good accuracy, average accuracy is $49.61 \%$ and dataset is so small and linear regression performs better as compared to other methods.
Table 2 Data and results (Bio Energy)

\begin{tabular}{lllll}
\hline Bioenergy production and accuracy & \multicolumn{3}{l}{} \\
\hline Data sets & Predicted data & $\begin{array}{l}\text { Current } \\
\text { production } \\
\text { (MW) }\end{array}$ & $\begin{array}{l}\text { Predicted } \\
\text { production } \\
\text { (MW) }\end{array}$ & Accuracy \\
\hline Bio Energy data of Russian Fed 2006-2016 & $2006-2030$ & 1370 & 1540.801 & 51.02 \\
Bio Energy data of Turkey 2006-2016 & $2006-2030$ & 395 & 626.7197 & 49.03 \\
Bio Energy data of Armenia 2006-2016 & $2006-2030$ & 0.00 & 0.74545 & 48.8 \\
Bio Energy data of Azerbaijan 2006-2016 & $2006-2030$ & 38 & 201.4236 & 49.03 \\
Bio Energy data of Eurasia 2006-2016 & $2006-2030$ & 1803 & 2491.216 & 50.18 \\
Average & Nil & 721.2 & 972.1811 & 49.61 \\
\hline
\end{tabular}


Acknowledgements The authors are grateful to the School of Computer Sciences, Anhui University Hefei, China for their support and cooperation. This work is not supported by any organization.

\section{Compliance with ethical standards}

Conflict of interest On behalf of all the authors, the corresponding author states that there is no conflict of interest.

\section{References}

1. Fisher B, Nakicenovic N, Alfsen K, Corfee-Morlot J, Riahi K (2007) Issues related to mitigation in the long-term context (Chapter 3 )

2. Scharlemann JP, Laurance WF (2008) How green are biofuels? Science 319(5859):43-44

3. Powlson DS, Gregory PJ, Whalley WR, Quinton JN, Hopkins DW, Whitmore AP, Hirsch PR, Goulding KW (2011) Soil management in relation to sustainable agriculture and ecosystem services. Food Policy 36:S72-S87

4. Yadav MP, Kale MS, Hicks KB, Hanah K (2017) Isolation, characterization and the functional properties of cellulosic arabinoxylan fiber isolated from agricultural processing by-products, agricultural residues and energy crops. Food Hydrocoll 63:545-551

5. González-García S, Bacenetti J (2019) Exploring the production of bio-energy from wood biomass. Italian case study. Sci Total Environ 647:158-168

6. Azar C (2005) Emerging scarcities-bioenergy-food competition in a carbon constrained world. In: Scarcity and growth revisited: natural resources and the environment in the new millennium, pp 98-120

7. Van Vuuren DP, Den Elzen MG, Lucas PL, Eickhout B, Strengers BJ, Van Ruijven B, Wonink S, van Houdt R (2007) Stabilizing greenhouse gas concentrations at low levels: an assessment of reduction strategies and costs. Clim Change 81(2):119-159

8. Beringer T, Lucht W (2008) Simulation nachhaltiger bioenergiepotentiale. Externe Expertise für das WBGU-Hauptgutachten „Welt im Wandel: Zukunftsfähige Bioenergie und nachhaltige Landnutzung", Berlin

9. Boddiger D (2007) Boosting biofuel crops could threaten food security. Lancet 370(9591):923-924

10. Dornburg V, Faaij A, Verweij P, Banse M, Diepen KV, Keulen HV, Langeveld H, Meeusen M, Ven Gvd, Wester F (2008) Biomass assessment: assessment of global biomass potentials and their links to food, water, biodiversity, energy demand and economy: inventory and analysis of existing studies: supporting document: MNP

11. Giampietro M, Ulgiati S, Pimentel D (1997) Feasibility of largescale biofuel production. Bioscience 47(9):587-600

12. Searchinger $T$, Heimlich $R$, Houghton RA, Dong F, Elobeid $A$, Fabiosa J, Tokgoz S, Hayes D, Yu T-H (2008) Use of US croplands for biofuels increases greenhouse gases through emissions from land-use change. Science 319(5867):1238-1240

13. Slesser M, Lewis C (1979) Biological energy resources: E. \& FN Spon

14. Smil V (2005) Energy at the crossroads: global perspectives and uncertainties. MIT Press, Cambridge

15. McCarl BA, Gillig D, Lee H-C, El-Halwagi M, Qin X, Cornforth GC (2005) Potential for biofuel-based greenhouse gas emission mitigation: rationale and potential. Agriculture as a Producer and Consumer of Energy. CABI Publishers, Cambridge
16. Anwar Z, Gulfraz M, Irshad M (2014) Agro-industrial lignocellulosic biomass a key to unlock the future bio-energy: a brief review. J Radiat Res Appl Sci 7(2):163-173

17. Rogner $H-H$, Barthel F, Cabrera M, Faaij A, Giroux M, Hall D, Kagramanian V, Kononov S, Lefevre T, Moreira R (2000) Energy resources. In: UNDP/UNDESA/WEC: Energy and the Challenge of Sustainability. World Energy

18. Berndes G, Hoogwijk M, Van den Broek R (2003) The contribution of biomass in the future global energy supply: a review of 17 studies. Biomass Bioenergy 25(1):1-28

19. Hoogwijk M, de Vries B, Turkenburg W (2004) Assessment of the global and regional geographical, technical and economic potential of onshore wind energy. Energy Econ 26(5):889-919

20. Smeets E, Faaij A (2004) Biomass resource assessment on global scale for identifying biomass production and export potentials. Copernicus Institute for Sustainable Development-Utrecht University, Utrecht

21. De Vries H, Hoogwijk M, Van Vuuren D (2007) The potential supply of renewable energy: wind, solar and bio-energy. Energy Policy 35(4):2590-2610

22. Smeets EM, Faaij AP, Lewandowski IM, Turkenburg WC (2007) A bottom-up assessment and review of global bio-energy potentials to 2050. Prog Energy Combust Sci 33(1):56-106

23. Gabisa EW, Gheewala SH (2018) Potential of bio-energy production in Ethiopia based on available biomass residues. Biomass Bioenergy 111:77-87

24. Glover JD, Culman SW, DuPont ST, Broussard W, Young L, Mangan ME, Mai JG, Crews TE, DeHaan LR, Buckley DH (2010) Harvested perennial grasslands provide ecological benchmarks for agricultural sustainability. Agric Ecosyst Environ 137(1-2):3-12

25. Jarchow ME, Liebman M, Dhungel S, Dietzel R, Sundberg D, Anex RP, Thompson ML, Chua T (2015) Trade-offs among agronomic, energetic, and environmental performance characteristics of corn and prairie bioenergy cropping systems. GCB Bioenergy 7(1):57-71

26. Ghosh SK (2016) Biomass \& bio-waste supply chain sustainability for bio-energy and bio-fuel production. Procedia Environ Sci 31:31-39

27. Gelfand I, Sahajpal R, Zhang X, Izaurralde RC, Gross KL, Robertson GP (2013) Sustainable bioenergy production from marginal lands in the US Midwest. Nature 493(7433):514

28. Jungers JM, Clark AT, Betts K, Mangan ME, Sheaffer CC, Wyse DL (2015) Long-term biomass yield and species composition in native perennial bioenergy cropping systems. Agron J 107(5):1627-1640

29. Carlsson G, Mårtensson LM, Prade T, Svensson SE, Jensen ES (2017) Perennial species mixtures for multifunctional production of biomass on marginal land. GCB Bioenergy 9(1):191-201

30. Yang $Y$ (2018) Prediction and analysis of aero-material consumption based on multivariate linear regression model. In: 2018 IEEE 3rd International Conference on Cloud Computing and Big Data Analysis (ICCCBDA). IEEE, pp 628-632

31. Iqbal MS, Luo B (2018) Prediction of educational institution using predictive analytic techniques. Educ Inf Technol 24:1469-1483

32. Izzah A, Sari YA, Widyastuti R, Cinderatama TA (2017) Mobile app for stock prediction using Improved Multiple Linear Regression. In: 2017 International Conference on Sustainable Information Engineering and Technology (SIET). IEEE, pp 150-154

33. Ergen T, Ceyani E (2018) A highly efficient recurrent neural network architecture for data regression. In: 2018 26th Signal Processing and Communications Applications Conference (SIU). IEEE, pp 1-4

34. Li L, Chu K-H (2017) Prediction of real estate price variation based on economic parameters. In: 2017 International Conference on Applied System Innovation (ICASI). IEEE, pp 87-90 
35. Amekraz Z, Youssef M (2016) Prediction of Amazon spot price based on chaos theory using ANFIS model. In: 2016 IEEE/ACS 13th International Conference of Computer Systems and Applications (AICCSA). IEEE, pp 1-6

36. Gao T, Li X, Chai Y, Tang Y (2016) Deep learning with stock indicators and two-dimensional principal component analysis for closing price prediction system. In: 2016 7th IEEE International Conference on Software Engineering and Service Science (ICSESS). IEEE, pp 166-169

37. Than $M M$, Thein $\mathrm{T}$ : Electricity price prediction for geographically distributed data centers in multi-region electricity markets. In: 2018 3rd International Conference on Computer and Communication Systems (ICCCS). IEEE, pp 89-93

38. Wang L, Chan FF, Wang Y, Chang Q (2016) Predicting public housing prices using delayed neural networks. In: 2016 IEEE Region 10 Conference (TENCON). IEEE, pp 3589-3592

39. Zafar S, Dincer I (2014) Energy, exergy and exergoeconomic analyses of a combined renewable energy system for residential applications. Energy Build 71:68-79
40. Demirbas Ayhan, Demirbas Burak (2016) Sustainable rural bioenergy production for developing countries. Energy Sources Part A Recovery Util Environ Eff 38(24):3578-3585

41. Colombo Guido, Ocampo-Duque William, Rinaldi Fabio (2014) Challenges in bioenergy production from sugarcane mills in developing countries: a case study. Energies 7(9):5874-5898

42. Surendra KC et al (2013) Household anaerobic digester for bioenergy production in developing countries: opportunities and challenges. Environ Technol 34(13-14):1671-1689

43. Kuchler Magdalena (2010) Unravelling the argument for bioenergy production in developing countries: a world-economy perspective. Ecol Econ 69(6):1336-1343

Publisher's Note Springer Nature remains neutral with regard to jurisdictional claims in published maps and institutional affiliations. 